\title{
THE EFFECT OF FINS PERFORATION AND MATERIAL TYPE ON THERMAL PERFORMANCE OF A HEAT SINK UNDER NATURAL CONVECTION \\ ${ }^{1}$ Maha Ali Hussein mahaali1984.84@gmail.com \\ ${ }^{1,2}$ Air Conditioning and Refrigeration University College
}

\section{ABSTRACT}

An experimental study was done to investigate the effect of fin geometry modification and material type on heat dissipation from a heat sink under natural convection. $\mathrm{v}$-corrugated solid fin and v-corrugated perforated fin were designed for this purpose. Aluminum and Copper metals were selected in designing the fins because their wide application in cooling and heating equipment. Three different voltages 110, 150 and $200 \mathrm{~V}$ supplied to the heat sink to study their effects on the fins performance. Each experiment repeats two times to reduce the error and the data recorded after reaching the steady state conditions. The utilization of solid and perforated v-corrugated fins is compared. The results showed that perforated fins dissipated heat more than corresponding solid by 15.4, 34 and $32 \%$ for aluminum, and 2.7, 2.1 and $4.3 \%$ for copper fin in the three voltages. Also, the results indicated that the heat loss by solid copper fin is greater by 56,72 and $92 \%$ than corresponding solid aluminum fin and for perforated fin case by $38,31.7$ and $51.9 \%$ at 110,150 and $200 \mathrm{~V}$ respectively.

Key word: Heat transfer dissipation, Heat sink, Extended surfaces, Heat transfer enhancements

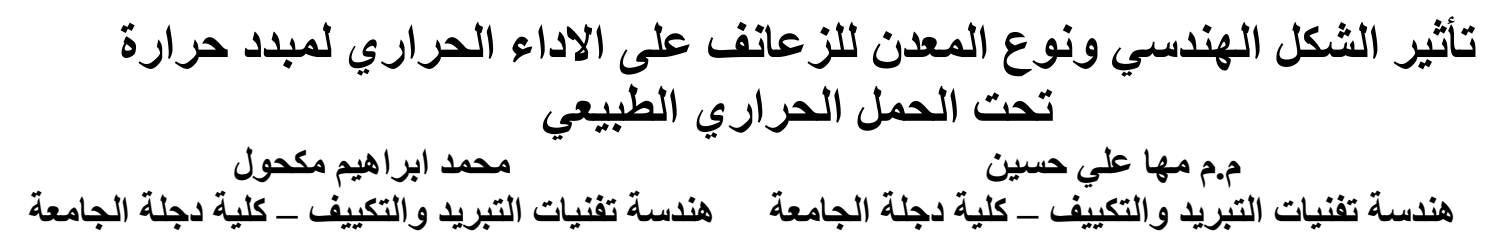

الخلاصة

اجريت دراسة تجريبية للتحقق في نأثير الثكل الهندسي للزعنفة و نوع المادة المستخدمة على فقدان الحرارة بواسطة

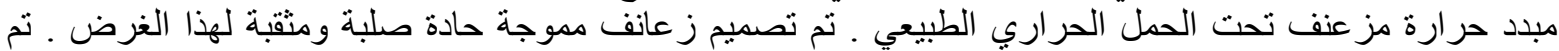

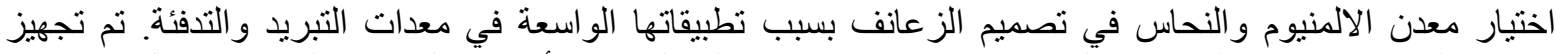

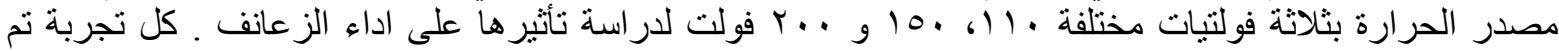

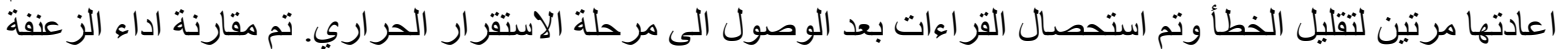

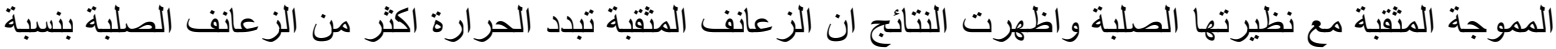

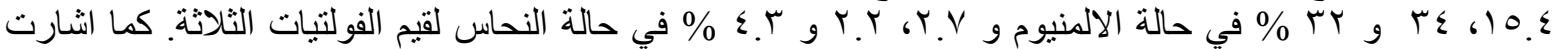

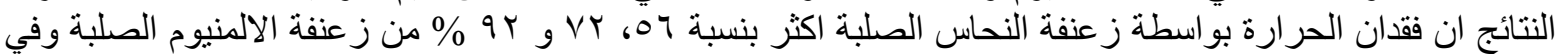

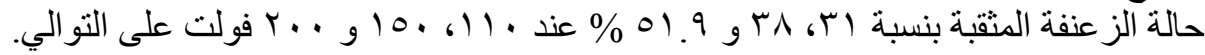

الكلمات الدالة: التبدد الحراري ، جهاز مبدد الحرارة ، السطوح الامتدادية ، تحسينات الانتقال الحراري 


\section{NOMENCLATURE}

$\begin{array}{ll}A & \text { Cross sectional area of the fin }\left(\mathrm{m}^{2}\right) \\ \mathrm{A}_{\mathrm{sf}} & \text { Area of solid fin }\left(\mathrm{m}^{2}\right) \\ \mathrm{A}_{\mathrm{pf}} & \text { Area of perforated fin }\left(\mathrm{m}^{2}\right) \\ \mathrm{A}_{\mathrm{c}} & \text { Inner surface area of cutting perforation }\left(\mathrm{m}^{2}\right) \\ \mathrm{d} & \text { Diameter }(\mathrm{m}) \\ \mathrm{g} & \text { Gravity acceleration }\left(\mathrm{m} / \mathrm{s}^{2}\right) \\ \mathrm{h} & \text { Heat transfer coefficient }\left(\mathrm{W} / \mathrm{m}^{2} .{ }^{\circ} \mathrm{C}\right) \\ \mathrm{k} & \text { Thermal conductivity }(\mathrm{W} / \mathrm{m} \cdot \mathrm{K}) \\ \mathrm{L} & \text { Length of the fin }(\mathrm{m}) \\ \mathrm{N}_{\mathrm{x}} & \text { Number of perforation in x-direction } \\ \mathrm{N}_{\mathrm{y}} & \text { Number of perforation in y-direction } \\ \mathrm{Nu} & \text { Nussult Number } \\ \mathrm{p} & \text { Perimeter of the fin }(\mathrm{m}) \\ \mathrm{Pr} & \text { Prandtl number } \\ \mathrm{q} & \text { Energy (W) } \\ \mathrm{Ra} & \text { Rayleigh number } \\ \mathrm{Ra} & \text { Rayleigh number of the perforation } \\ \mathrm{t} & \text { Thickness of the fin }(\mathrm{mm}) \\ \mathrm{T}_{\mathrm{s}} & \text { Temperature of fin surface } \\ \mathrm{T}_{\infty} & \text { Ambient Temperature } \\ \mathrm{T}_{\mathrm{f}} & \text { The film temperature } \\ \mathrm{W} & \text { Width of the fin }(\mathrm{m}) \\ v & \text { Kinematic viscosity }\left(\mathrm{m}^{2} / \mathrm{s}\right) \\ & \end{array}$

\section{INTRODUCTION}

Excess heat is a series problem in electronic and mechanical devices, and this problem increases when these devices are unable to lose heat to moderate their temperature. Heat sink is considered as a passive technology, which is used to transfer heat from hot part to the surrounding, Sonawane et.al [2016]. To achieve a high performance for a heat sink, there are some consideration should be considered in designing it like, type of material, the fluid velocity in the surrounding and the surface area that contact the cooling surrounding medium.

Extended surfaces such as fins are used in designing a heat sink in order to increase its surface area. In order to increase the heat transfer rate to a fin heat sink, there are two ways. Firstly, increase the surface area of the fin. Secondly, increase the heat transfer coefficient of the fin. The fin geometry, materials, spacing and arrangement had a great interest by many researchers.

Dewan et. al [2009] studied the thermal performance analysis of a flat heat sink with circular pin fin. Reynolds numbers are used from 200 to 1000 to investigate their influence on thermal behavior. Also, different materials were used in designing fins. The results showed that high heat transfer rate was achieved with fins which have large thermal conductivity under the same conditions.

Bahadure and Gosavi [2014] investigated theoretically and experimentally the effect of material type, arrangement and number of perforation on the thermal performance of a pin fin heat sink under natural convection. The results indicated that more enhancement was obtained by using material with high thermal conductivity and by using high number of perforation.

Prabisha and Ramesh [2015] modeled a new design of a heat sink and analyzed it through simulation software. They used a new fin profiles like straight, pin, corrugated, continuous and interrupted fin heat sink. The fins were made from Aluminum and Copper under the same conditions. The simulation results showed that tapered heat sink is more efficient to dissipate heat and the corrugated one had the high effectiveness as compared to others. 
Muthuraja et.al [2015] examined experimentally the heat dissipation from a vertical perforated aluminum fin under natural convection. The geometrical and thermal properties as well as the shape of perforations were considered. The results showed that fins with circular perforation are more efficient in dissipation heat than the solid one.

Shitole and Arkirimath [2016] introduced a new modeling of a fin heat sink. They use different shape and size perforation (square, circular and triangular) in a vertical aluminum fin under natural convection. The perforation area range from 33.2 to $176.8 \mathrm{~mm}^{2}$ with various power supplies (60-120 W). The results showed that circular perforation had the higher value of heat transfer coefficient than other shapes. Also, the heat dissipation increases as the area of perforation increases.

Prasad et.al [2016] investigated the effect of perforation number on heat transfer rate for a heat sink under natural convection. They used aluminum flat fins with perforation number range from 24 to 60 . The results indicated that heat transfer rate is increased about $20 \%$ to $70 \%$ with increase number of perforation.

The aim of this study is to investigate experimentally the effect of circular perforation through vcorrugated fin on heat transfer rate as compared to the corresponding solid one. Also, examine the influence of thermal properties of two type fin's material (Aluminum and Copper) on the heat sink performance.

\section{EXPERIMENT DETAILES}

\section{Rig Construction}

There are many consideration were taken in designing a finned heat sink used in this work such as, the heat source is centered inside the heat sink and has perfect contact with it, the total surface area of the finned heat sink is much greater than the fin thickness and source thickness, finally use v-corrugated fin with sharp corner to achieve size reduction and high performance, Ralph and Kim [2005].

The v-corrugated fin made from pure aluminum and pure copper were designed and mounted vertically around a cylindrical heat sink through a slot $(250 \mathrm{~mm}$ height and $5 \mathrm{~mm}$ deep) made around the cylinder. The fins are $25 \mathrm{~cm}$ long and $25 \mathrm{~cm}$ width with $3 \mathrm{~mm}$ thickness. Two fins are solid and the others are perforated with 27 circular holes (inline arrangement) with $1 \mathrm{~cm}$ in diameter as can be seen in Figure(1). A cylindrical heat sink which made from aluminum with $6 \mathrm{~cm}$ diameter and $40 \mathrm{~cm}$ length was fixed inside insulation block to depth of $15 \mathrm{~cm}$. A heating element 800 watt and $1.5 \mathrm{~cm}$ in diameter is fitted centrally inside the aluminum cylinder by drilling the cylinder to a depth $25 \mathrm{~cm}$. Figure(2) shows the experimental setup. A power supply with manual voltage regulator was used to regulate the voltage supplied to the heating element. 26 thermocouples of k-type were used by placing 6 thermocouples on the fin surface at equal spacing $(4 \mathrm{~cm})$. The heat sink surface and surrounding temperatures are also measured by two different thermocouples. The specifications for all rig parts listed in Table.1.

\section{Experimental Procedure}

The voltage regulator used to supply the heating element with three different voltages 110, 150 and 200 volts. Heat is continuously and equally transferred from the hot cylinder to the fins. After achieving the steady state condition, no more change in the temperature occurs along the fin. The same procedures are repeated for 150 and $200 \mathrm{~V}$. The experimental run repeated two times for each supply voltage to increase the run accuracy and eliminate the errors. It is very important to calibrate the thermocouples before placed them to the fins. A mercury thermometer was used for this purpose. 


\section{DATA PROCESSING}

In order to analysis the heat transfer for corrugated solid and corrugated perforated fins, the following assumptions are considered:

1- There is no heat generation across the fin.

2- The thermal conductivity of the fin is constant.

3- Uniform base and ambient temperature.

4- Uniform heat transfer coefficient along the fin.

At steady state condition with respect to previous assumptions, the amount of heat conducted from the fin base to its tip is equal to the heat convective from the surface area of the fin. The energy balance of the fin can be expressed as:

Energy conducted from base to tip = Energy lost by convection

Where,

Energy conducted from base to tip $=k A \frac{d T}{d x}$

Energy lost by convection $=h A_{s}\left(T_{s}-\stackrel{d x}{T_{\infty}}\right)$

The heat transfer coefficient is calculated from equation (1) and its value can be increased by change the fin geometry. The fin surface area $\left(\mathrm{A}_{\mathrm{s}}\right)$ for a solid and perforated corrugated fin (Fig.1) can be calculated as follow:

For solid fin:

$$
A_{s f}=2(L . W)+2(L . t)+W \cdot t
$$

For perforated fin:

$$
\begin{aligned}
A_{p f} & =A_{s f}+A_{c}-2 \cdot N_{x} \cdot N_{y^{*}} \cdot A_{p} \\
& =A_{s f}+\pi d t-2 \cdot N_{x} \cdot N_{y^{*}}\left(\frac{\pi}{4} d^{2}\right)
\end{aligned}
$$

The heat flow through the fin can be measured by using the equation of infinite length as follows, Holman, 2010:

$q=\sqrt{h p k A}\left(T_{o}-T_{\infty}\right) \frac{\sinh m L+\left(\frac{h}{m k}\right) \cosh m L}{\cosh m L+\left(\frac{h}{m k}\right) \sinh m L}$

Let $m=\sqrt{\frac{h p}{k A}} \approx \sqrt{\frac{2 h}{k t}}$

But the length of the fin is corrected by the following:

$L_{c}=L+\frac{t}{2}$

To compare the experimental data with empirical corresponding data, the following analytical equations are required:

For free convection from a solid vertical fin, Churchill and Chu, Holman, 2010 provided an empirical complicated relation for $10^{-1}<R a<10^{12}$.

$N u=\left[0.825+\frac{0.387 \mathrm{Ra}^{\frac{1}{6}}}{\left[1+\left(\frac{0.992}{P r}\right)^{\frac{9}{16}}\right]^{\frac{8}{27}}}\right] 2$

$R a=\frac{g \cdot \beta \cdot\left(T_{S}-T_{\infty}\right) W^{3}}{v^{2}} . P r$

Where:

$\beta=1 / T_{f}$

$g=9.81 \mathrm{~m} / \mathrm{s}^{2}$

$\mathrm{Pr}=$ prandtle number for air at film temperature

$v=$ Kinematic viscosity for air at film temperature $\left(\mathrm{m}^{2} / \mathrm{s}\right)$

In case of the perforated fin there are two heat transfer coefficients. The first one for the solid space of the fin which can be expressed as, Thamir et.al, 2016, and Jassem, 2013: 


$$
\left(h_{s}\right)_{p f}=(1+0.75 R O A) \cdot h
$$

where ROA is the ratio of open area and can be calculated by dividing the actual open area on the max. open area of the perforation as follows:

$R O A=\frac{N_{x} N_{y i} A_{c}}{\left(N_{x} N_{y}\right)_{\max } A_{c}}$

Where $\left(N_{x} N_{y}\right)_{\max }$ can be achieved by making the space between holes equal zero.

The second heat transfer coefficient within the perforation can be calculated from, AlEssa, 2012:

$N u_{c}=\left[\left(\frac{R a_{c}}{16}\right)^{-1.03}+\left(0.62 . R a_{c}{ }^{0.25}\right)^{-1.03}\right]^{\frac{1}{1.08}}$

The average heat transfer coefficient can be obtained from:

$h=\frac{N u \cdot k}{L}$

\section{RESULTS AND DISCUSSION}

This work conducted to predict the effect of fin geometry and material type on the heat transfer rate of a heat sink under natural convection. The v-corrugated profile was chosen because it was reported that heat transfer rate for a non flat plate is higher by $50 \%$ to $100 \%$ than the flat plate Rahsenow et.al, 1998. Also, the v-corrugated plate provides thermal mixing due to its boundary layer separation Xuan et.al, 2001. The adopted fins materials were aluminum and copper because their availability and they have been used in a wide range in heating and cooling equipments. The perforated fin designed in this study enhanced the heat transfer coefficient of the plate as these circular perforations formed boundary layer dissipation in the wake region Kraus et.al, 2001. Table 2 illustrates the experimental calculated parameters for this study and the following sections will discuss in brief the results obtained.

\section{The Model Validity}

Figure(3) and Figure(4) illustrate the model validation of aluminum and copper fins respectively by comparing the theoretical and experimental heat transfer coefficient values in three voltages supply. As can be clearly seen, the experimental results consider as a good agreement as compared with the corresponding theoretical results calculated from analytical equations. The percentage error for the aluminum fins: (a) solid v-corrugated fin with $3.8 \%$ average error (b) v-corrugated perforated fin with $3.8 \%$ average error. On the other hand, the percentage error for the copper fin: (a) solid v-corrugated fin with $13.5 \%$ average error (b) vcorrugated perforated fin with $6.9 \%$ average error.

\section{Effect of Perforation on Heat Transfer Rate}

Figure(5) and Figure(6) show the temperature distribution along aluminum and copper fins respectively. For both materials the surface temperature of the perforated fin decreases along the fin from the base to the tip in all three voltages supply. The perforated aluminum fin gives higher temperature difference about $10 \%$ more than the solid one and $8 \%$ for the perforated copper fin. This happen because the perforated fin is not only surrounded by air, but it allow the air to pass across the fin through its perforation in many places to take more heat from the fin. In other word, perforations through the fin increase the ventilation between the hot fin surface with the surrounding.

Figure(7) illustrates the heat transfer coefficient for aluminum and copper fin in three different voltages. As can be seen, the heat transfer coefficient for aluminum perforated fin is 27 $\%, 24 \%$ and $19 \%$ greater than non- perforated, as well as the perforated copper fin is $27 \%, 20$ $\%$ and $19 \%$ greater than non-perforated at 110, $150200 \mathrm{~V}$ respectively. The reason for that, the perforation fins have two independent heat transfer coefficient. The first one associated with the perforation and the second within the solid portion among the perforation. 
Fig. 8 presents the energy loss from the aluminum and copper perforated and nonperforated fins with three voltages supply. In the aluminum fins, the perforated fin dissipates heat greater than the corresponding solid by $15.4 \%, 34 \%$ and $32 \%$ for 110,150 and $200 \mathrm{~V}$ respectively. Also, for copper the amount of heat loss from the fin to the surrounding is higher in perforated fin by $2.7 \%, 2.1 \%$ and $4.3 \% \%$ for 110,150 and $200 \mathrm{~V}$ respectively. Because the perforated fin have the biggest heat transfer coefficient.

\section{Effect of Fins Material Types on Heat Transfer Rate}

In this study, for similar fin shape, dimensions and system operation conditions, aluminum fins reached the steady state after $30 \mathrm{~min}$. Otherwise; the copper fins reached the steady state after $45 \mathrm{~min}$. The reason for that, copper absorbs more heat from the heat sink due to its higher density and thermal conductivity and maintains this heat in a uniform distribution along the fin. Unlike the aluminum fin which absorbs less heat from the heat sink than copper and tend to dissipate this heat faster than copper did.

Figure(9) and Figure(10) compare the temperature distribution along the aluminum and copper fins (a) for solid plate (b) for perforated plate, in three voltages supply. As can be seen, the temperature difference along the aluminum solid fins is higher than copper solid one by $16 \%$ and by $15 \%$ for perforated fin. In other words, the copper fin will absorb more heat from the heat sink due to its high thermal conductivity and this heat conducted along the fin and rise the fin surface temperature. But, the aluminum fin takes less heat from the heat sink and faster rejects it to the surrounding.

Figure(11) shows the heat transfer coefficient for the aluminum and copper (solid and perforated) for $110 \mathrm{~V}$. As can be seen from the column bar, the heat transfer coefficient values of the copper fins (both geometry) are greater than of aluminum fins by $12.9 \%$ and $12.6 \%$ for solid and perforated fins respectively. The reason for that, the copper fins surface temperature is higher than aluminum during the steady state condition. Therefore, the difference temperature between the ambient and surface is high and that lead to increase the heat transfer coefficient.

Figure(12) presents a comparison of a heat loss by the aluminum and copper fins at $200 \mathrm{~V}$. The perforated copper fin has the great heat dissipation among the other fin and the copper fins are loss heat by $92 \%$ and $51.9 \%$ more than aluminum fin for non perforated and perforated fin respectively.

\section{CONCLUSIONS}

From the previous discussion which dependent on the results shown in Table. 2 it can be concluded that:

1. The temperature difference along the perforated fin is higher than the equivalent solid.

2. Higher heat transfer dissipation achieved by using perforation fins than non-perforation due to their high heat transfer coefficients. For aluminum, average heat transfer coefficient for perforated fin is 27,24 and $19 \%$ greater than solid fin and for copper is 27, 20 and $19 \%$.

3. For copper and aluminum fins identical geometry, the heat transfer coefficient for copper is higher by $12.9,15.3$ and $13.4 \%$ than for aluminum for solid fin and by 12.6, 11 and $13.7 \%$ for perforated fin.

4. The heat loss by solid copper fin is grater by 56,72 and $92 \%$ than corresponding solid aluminum fin and by $38,31.7$ and $51.9 \%$ for perforated fins case. 


\section{ACKNOWLEDGEMENTS}

The researchers would like to express great appreciation to Mr. Hayman Abd Ali for providing remarkable support in the practical part of this study.

Table.1 The specification of rig parts

\begin{tabular}{|c|c|}
\hline $\begin{array}{l}\text { Power supply } \\
\text { Origin: China (manual) } \\
\text { Input: single phase }(220 \mathrm{~V}) \\
\text { Output: } 0-250 \mathrm{~V} \\
\quad \text { Ac current }(2 \mathrm{~A}) \\
\text { Frequency: } 50 / 60 \mathrm{~Hz}\end{array}$ & $\begin{array}{l}\text { Heated element } \\
\text { Material: steel } \\
\text { Power: } 800 \mathrm{~W}(\max .) \\
\text { Dimensions: }(1.5 \mathrm{~cm}) \text { diameter } \\
\qquad \quad(25 \mathrm{~cm}) \text { length }\end{array}$ \\
\hline $\begin{array}{l}\text { Heat sink } \\
\text { Material: Aluminum } \\
\text { Shape: cylinder } \\
\text { Dimensions: }(6 \mathrm{~cm}) \text { diameter } \\
\qquad(40 \mathrm{~cm}) \text { length }\end{array}$ & $\begin{array}{l}\text { Thermocouple } \\
\text { Type: } \mathrm{k} \text { type }(\mathrm{NiCr}-\mathrm{NiAl}) \\
\text { Range: }-10 \text { to } 800{ }^{\circ} \mathrm{C} \\
\text { Accuracy: } \pm 2{ }^{\circ} \mathrm{C}\end{array}$ \\
\hline $\begin{array}{l}\text { Fins } \\
\text { Materials: Aluminum, Copper } \\
\text { Dimensions: } 25 \times 25 \mathrm{~cm} \\
\text { Shapes: v-corrugated (solid) } \\
\quad \text { v-corrugated with } 10 \mathrm{~mm} \\
\quad \text { diameter perforation }\end{array}$ & $\begin{array}{l}\text { Data screen } \\
\text { Power supply: } 220 \mathrm{~V}, 50 / 60 \mathrm{~Hz} \\
\text { Display method: } 7 \text { segment LED } \\
\text { Accuracy: } \pm 1 \text { digit } \\
\text { Range: } 0-1200^{\circ} \mathrm{C}\end{array}$ \\
\hline
\end{tabular}

Table.2 Experimental calculated parameters

\begin{tabular}{|c|c|c|c|c|c|}
\hline $\begin{array}{c}\text { Material of } \\
\text { fin }\end{array}$ & Type of fin & $\begin{array}{c}\text { Voltages } \\
\text { supplied }\end{array}$ & $\Delta \mathrm{T}\left({ }^{\circ} \mathrm{C}\right)$ & $\mathrm{h}\left(\mathrm{W} / \mathrm{m}^{2} \cdot{ }^{\circ} \mathrm{C}\right)$ & $\mathrm{Q}_{\text {loss }}(\mathrm{W})$ \\
\hline \multirow{4}{*}{ Aluminum } & \multirow{3}{*}{ solid } & 110 & 54 & 6.2 & 24.33 \\
\cline { 3 - 6 } & & 150 & 94 & 6.5 & 40.47 \\
\cline { 3 - 6 } & \multirow{3}{*}{ perforated } & 200 & 120 & 6.7 & 52.87 \\
\cline { 3 - 6 } & & 110 & 57 & 7.9 & 28.09 \\
\cline { 3 - 6 } & & 150 & 97 & 8.1 & 54.28 \\
\hline \multirow{3}{*}{ Copper } & \multirow{3}{*}{ solid } & 110 & 126 & 8 & 70 \\
\cline { 3 - 6 } & & 150 & 86 & 7 & 37.96 \\
\cline { 3 - 6 } & \multirow{3}{*}{ perforated } & 200 & 122 & 7.5 & 70.2 \\
\hline & & 110 & 46 & 8.9 & 101.91 \\
\hline & & 150 & 88 & 9 & 71.5 \\
\hline
\end{tabular}




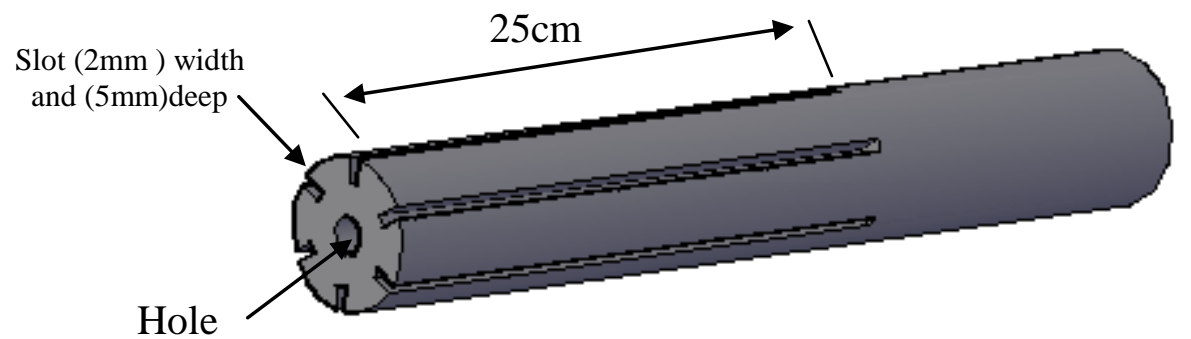

(15 mm)Dia.

(a)

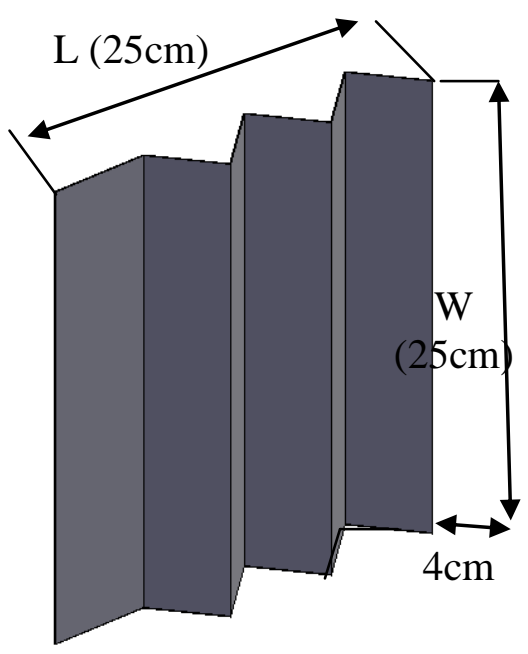

(b)

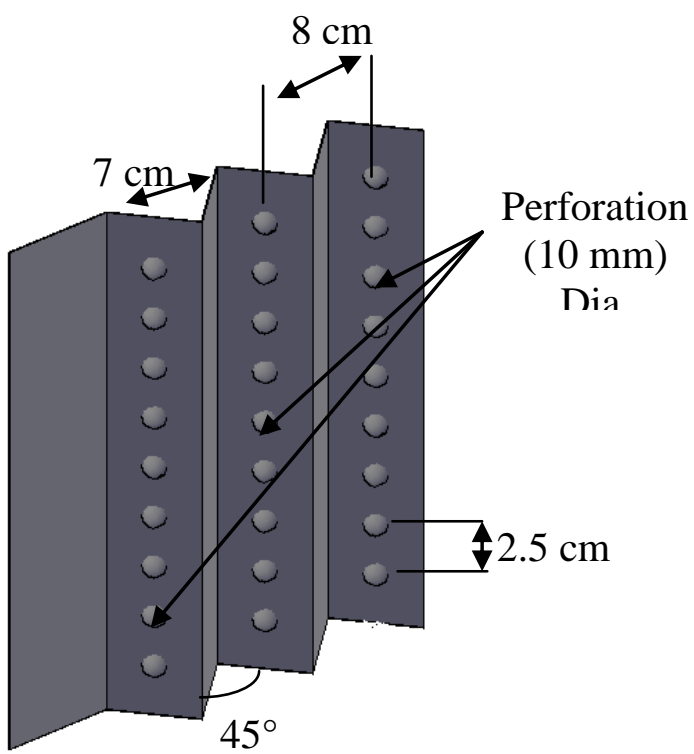

(c)

Fig.1. Schematic 3D rig(a) cylindrical heat sink (b) solid corrugated fin (c) perforated fin

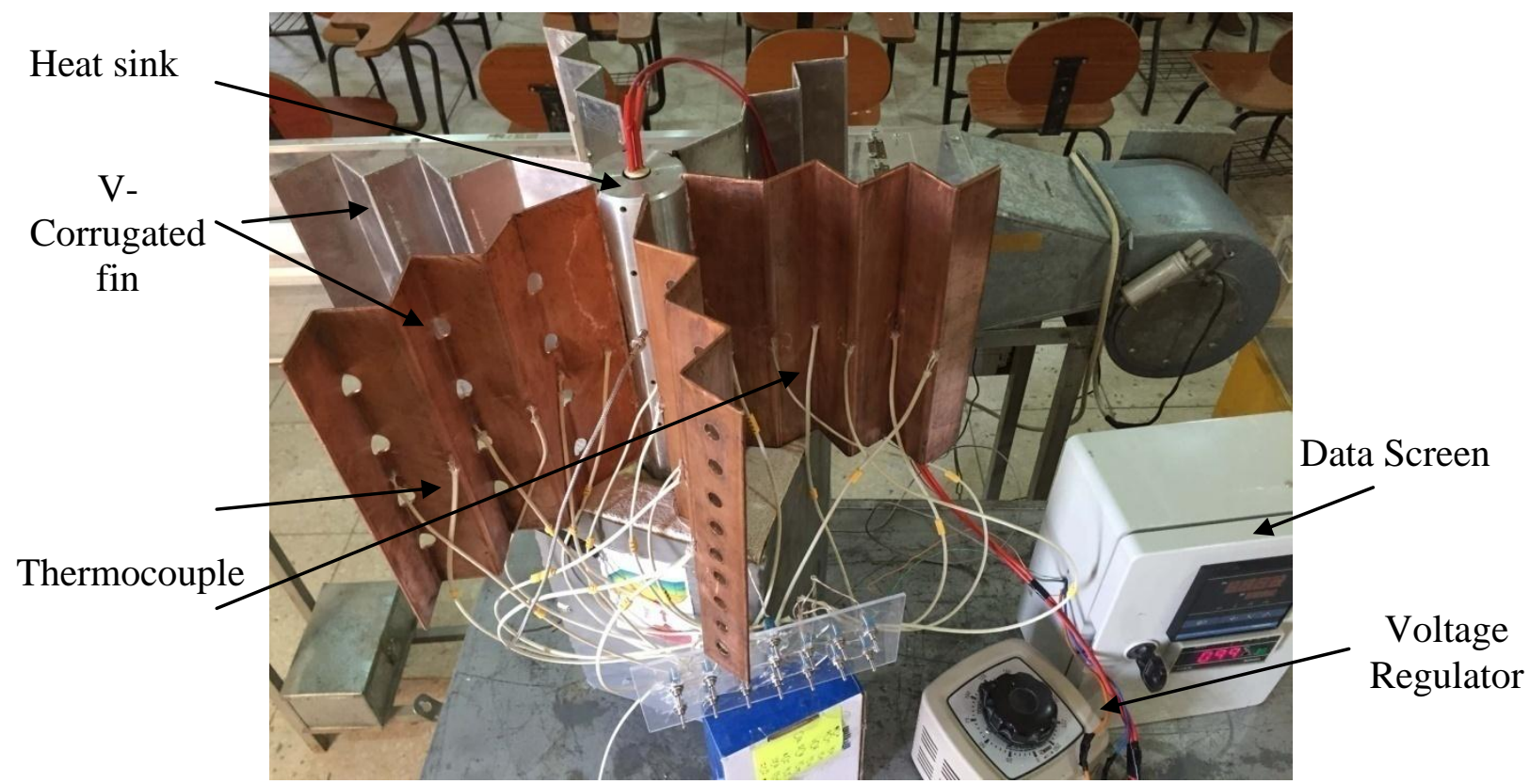

Fig.2. Experimental setup 

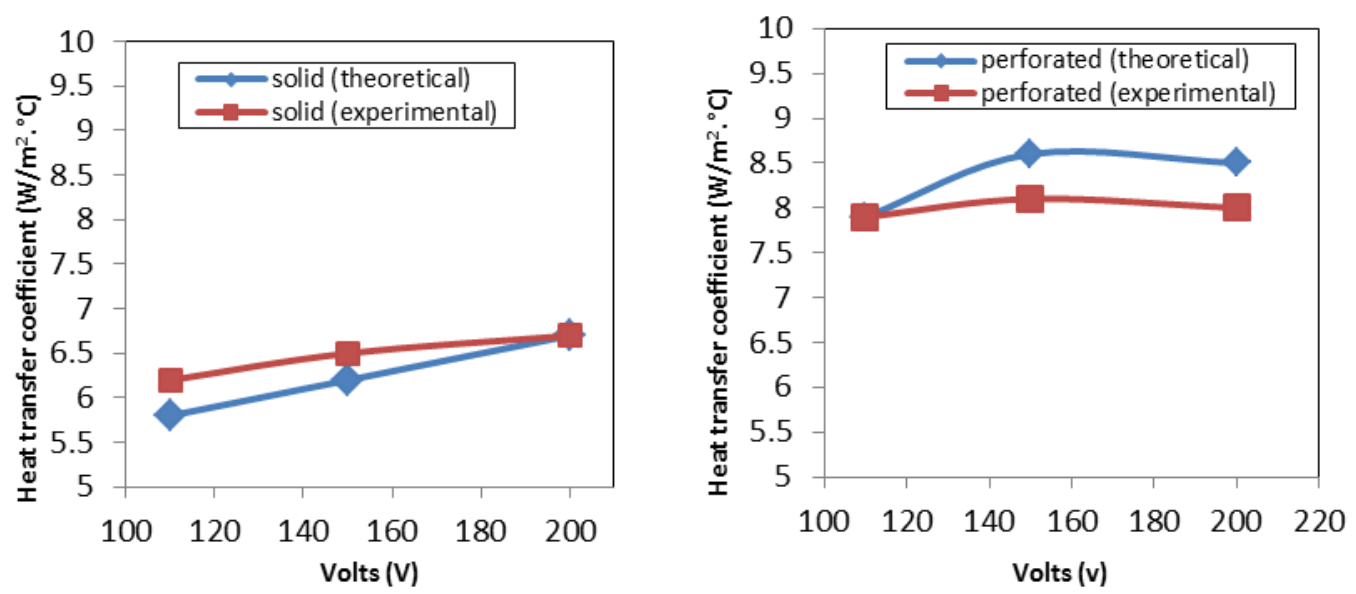

Fig.3. Theoretical and experimental heat transfer coefficient vs. volts for aluminum fins
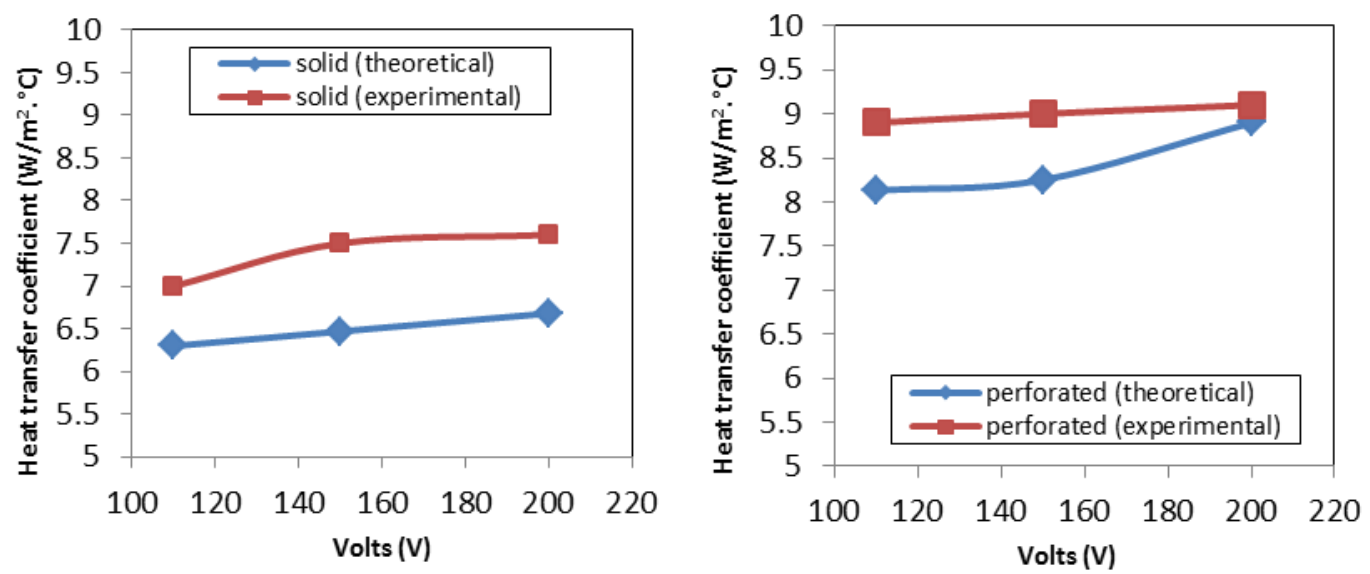

Fig.4. Theoretical and experimental heat transfer coefficient vs. volts for copper fins

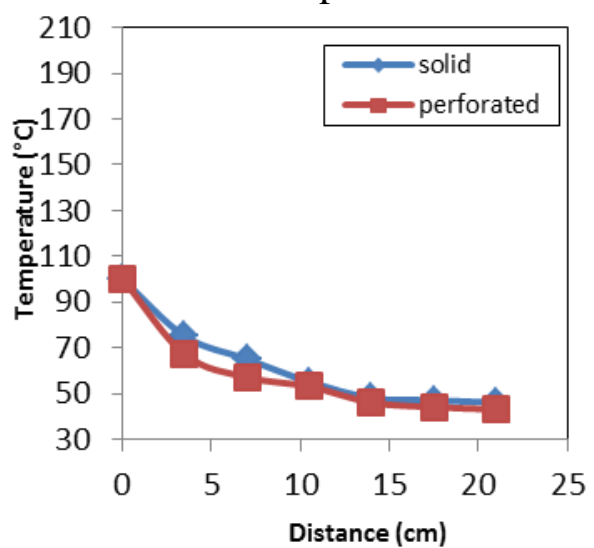

(a)

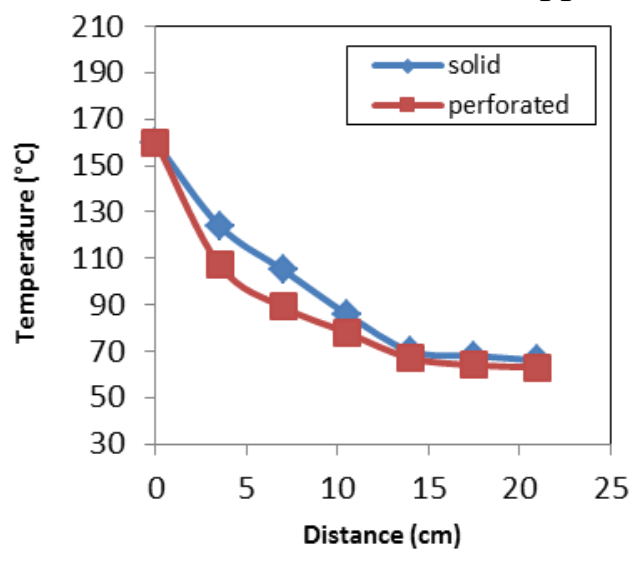

(b) 


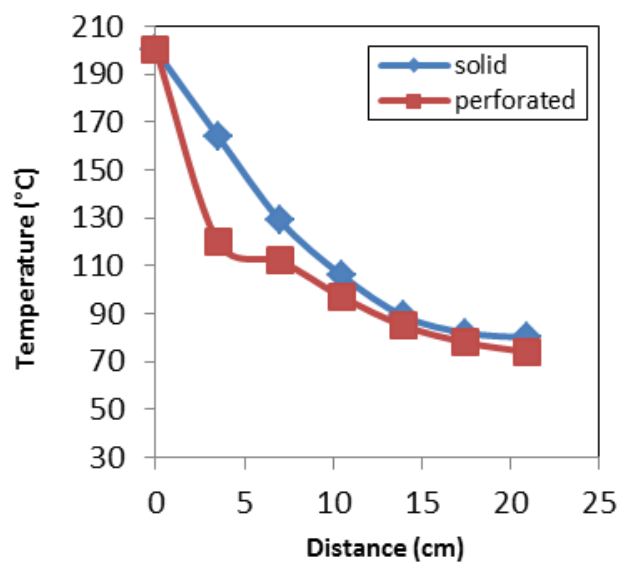

(c)

Fig.5. Temperature distribution along the aluminum fins at (a) $110 \mathrm{~V}$ (b) $150 \mathrm{~V}$ (c) $200 \mathrm{~V}$

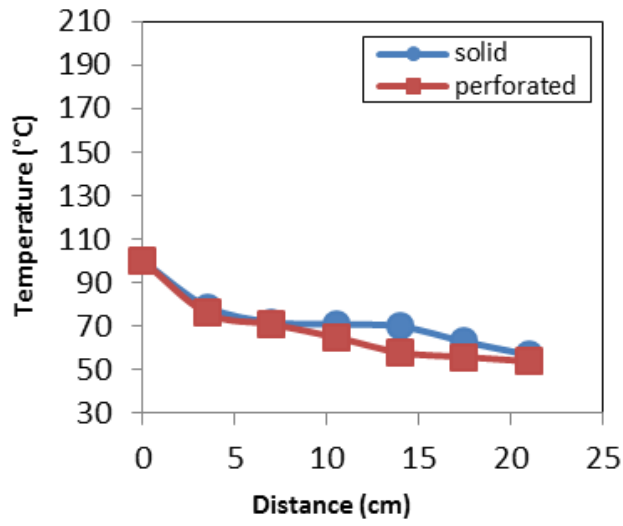

(a)

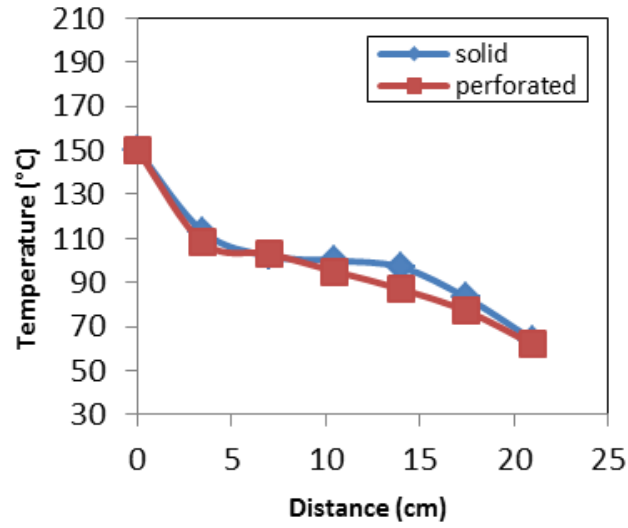

(b)

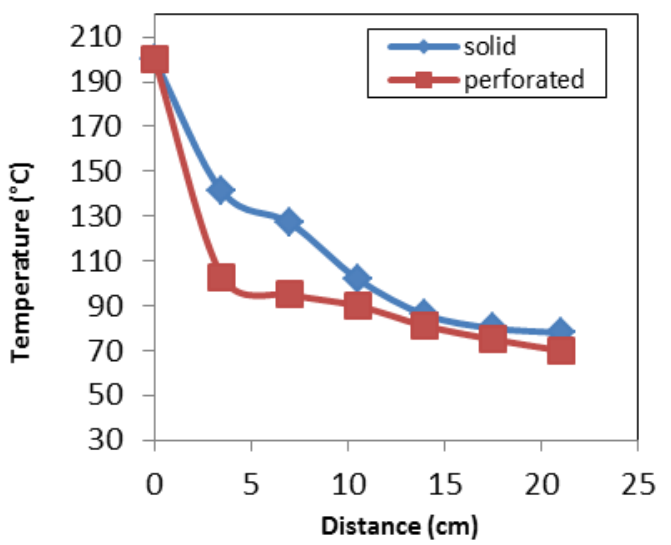

(c)

Fig.6. Temperature distribution along the copper fins at (a) $110 \mathrm{~V}$ (b) $150 \mathrm{~V}$ (c) $200 \mathrm{~V}$ 


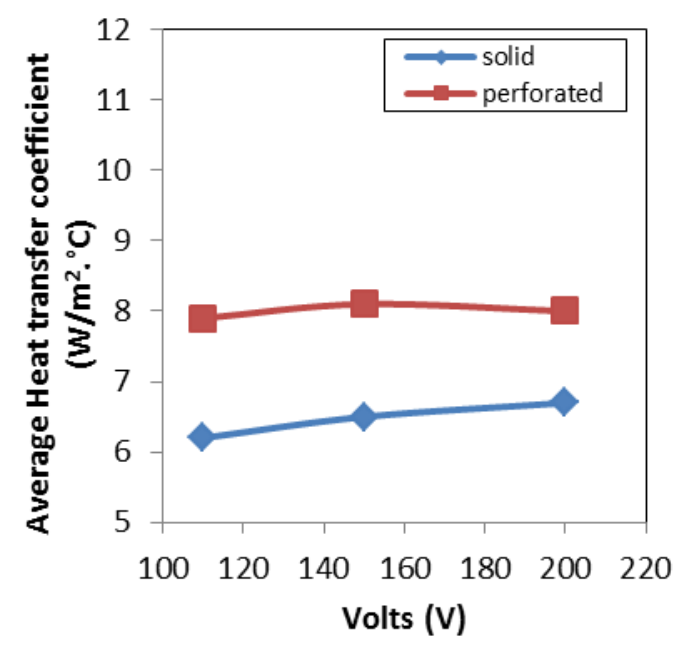

(a)

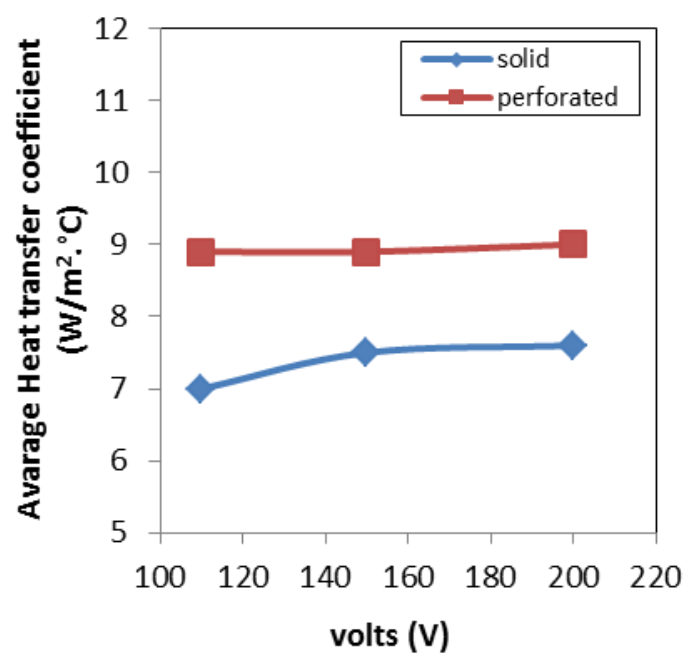

(b)

Fig.7. Average heat transfer coefficient vs. volts for (a) aluminum (b) copper

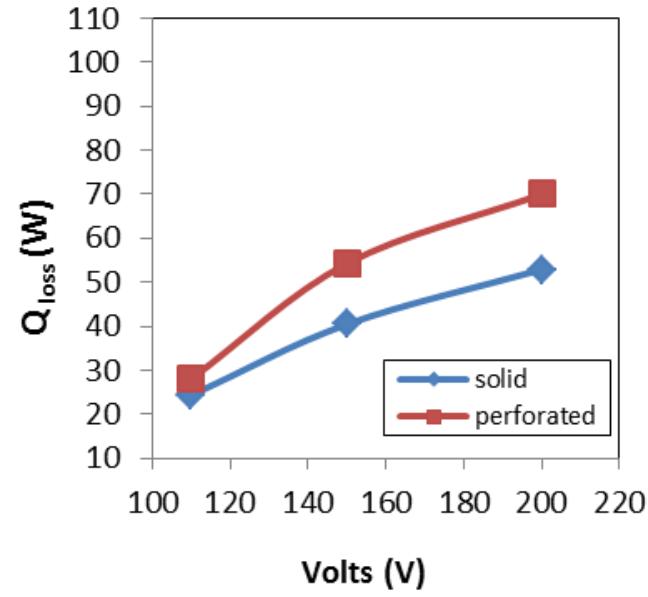

(a)

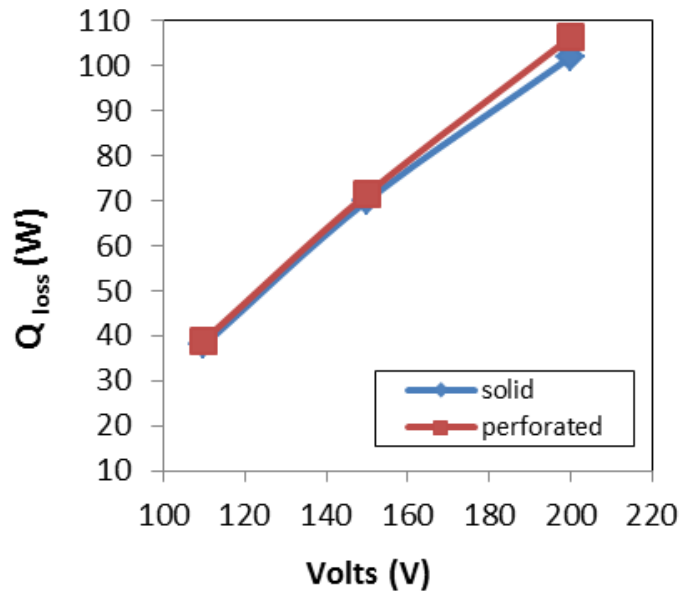

(b)

Fig.8. Heat loss vs. volts for (a) aluminum (b) copper

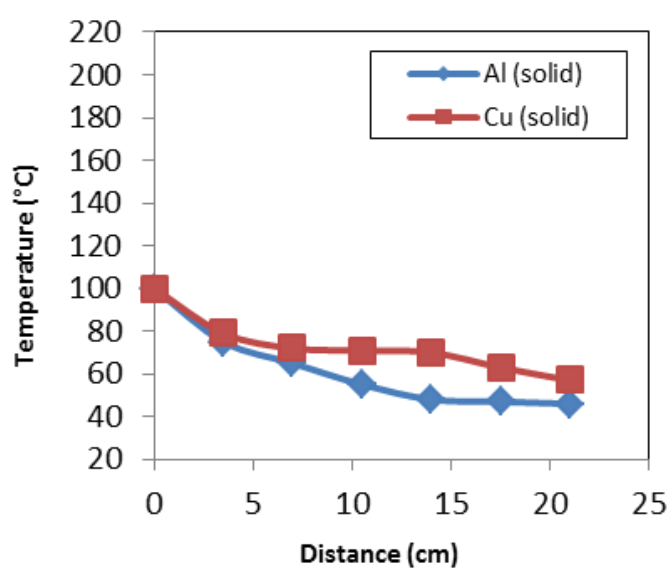

(a)

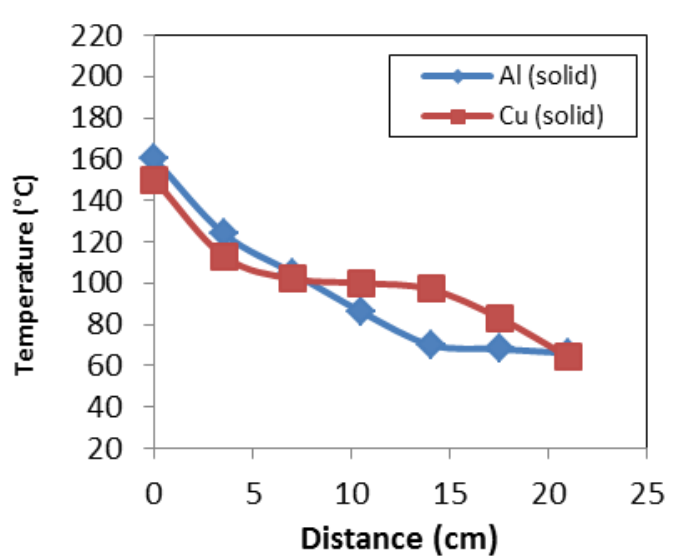

(b) 


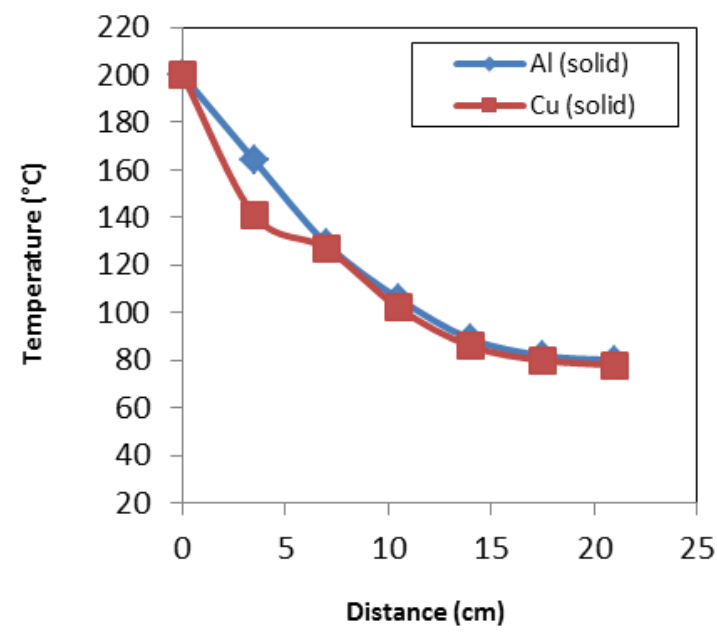

(c)

Fig.9. Comparison between the temperature distribution along $\mathrm{Al}$ and $\mathrm{Cu}$ solid fins (a) $110 \mathrm{~V}$ (b) $150 \mathrm{~V}$ (c) $200 \mathrm{~V}$

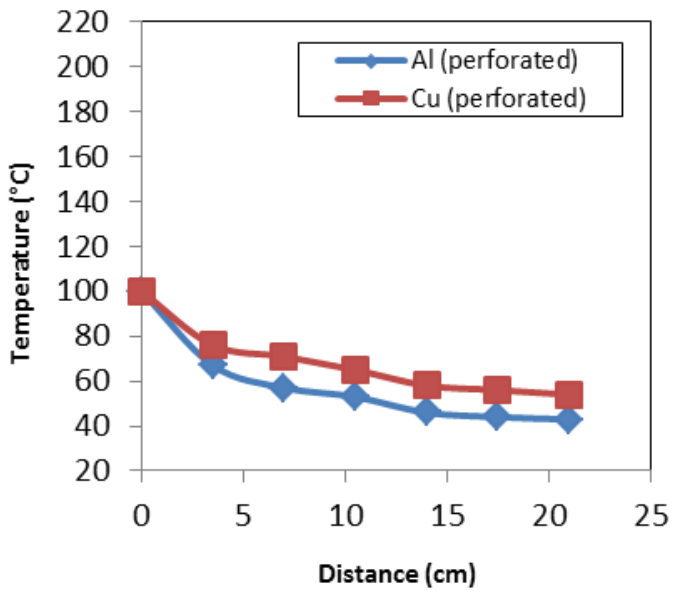

(a)

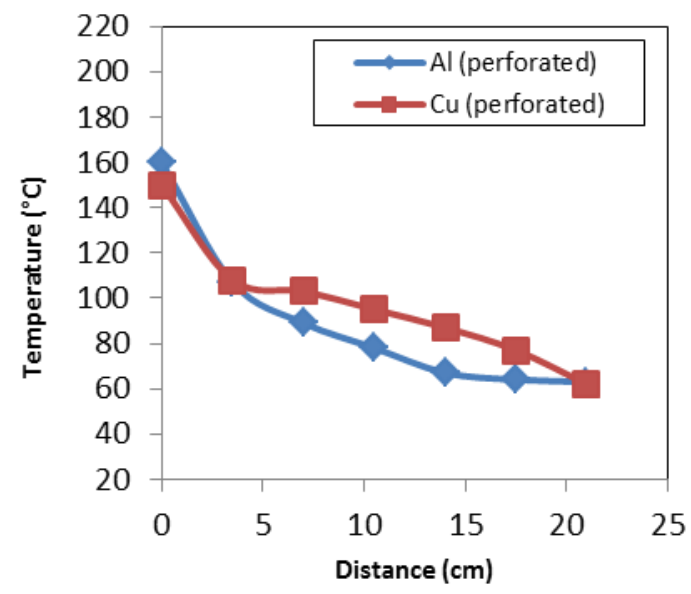

(b)

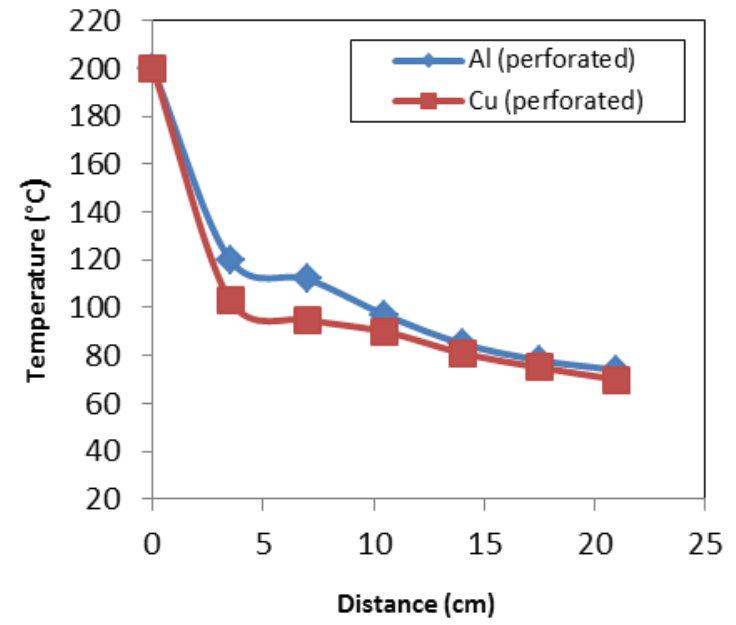

(c)

Fig.10. Comparison between the temperature distribution along $\mathrm{Al}$ and $\mathrm{Cu}$ perforated fins (a) $110 \mathrm{~V}$ (b) $150 \mathrm{~V}$ (c) $200 \mathrm{~V}$ 


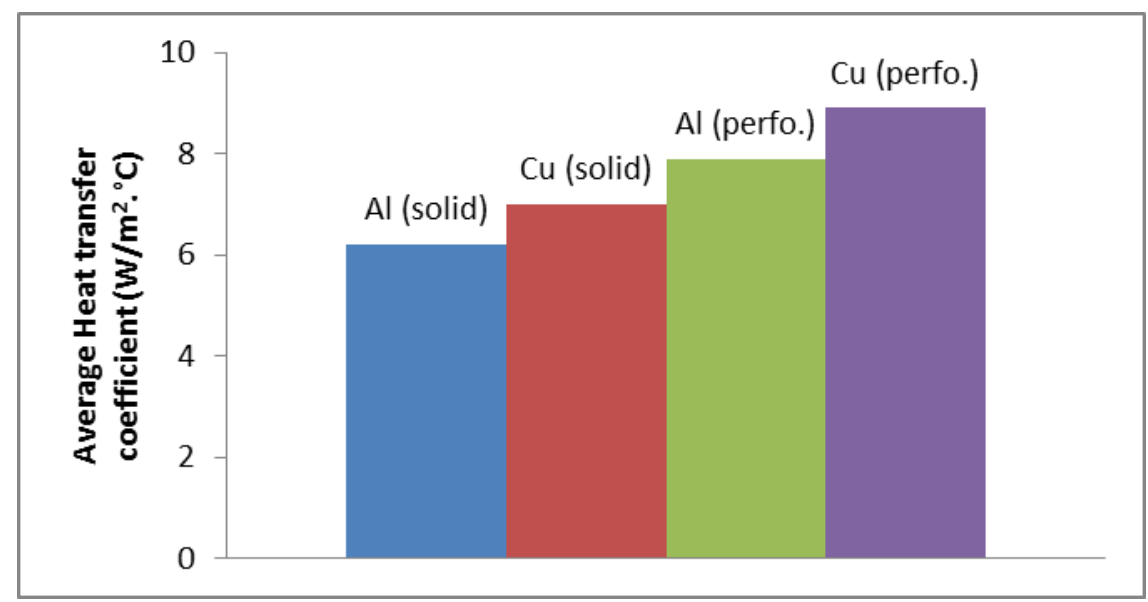

Fig.11. Comparison between Average heat transfer coefficient for $\mathrm{Al}$ and $\mathrm{Cu}$ fins (solid and perforated)

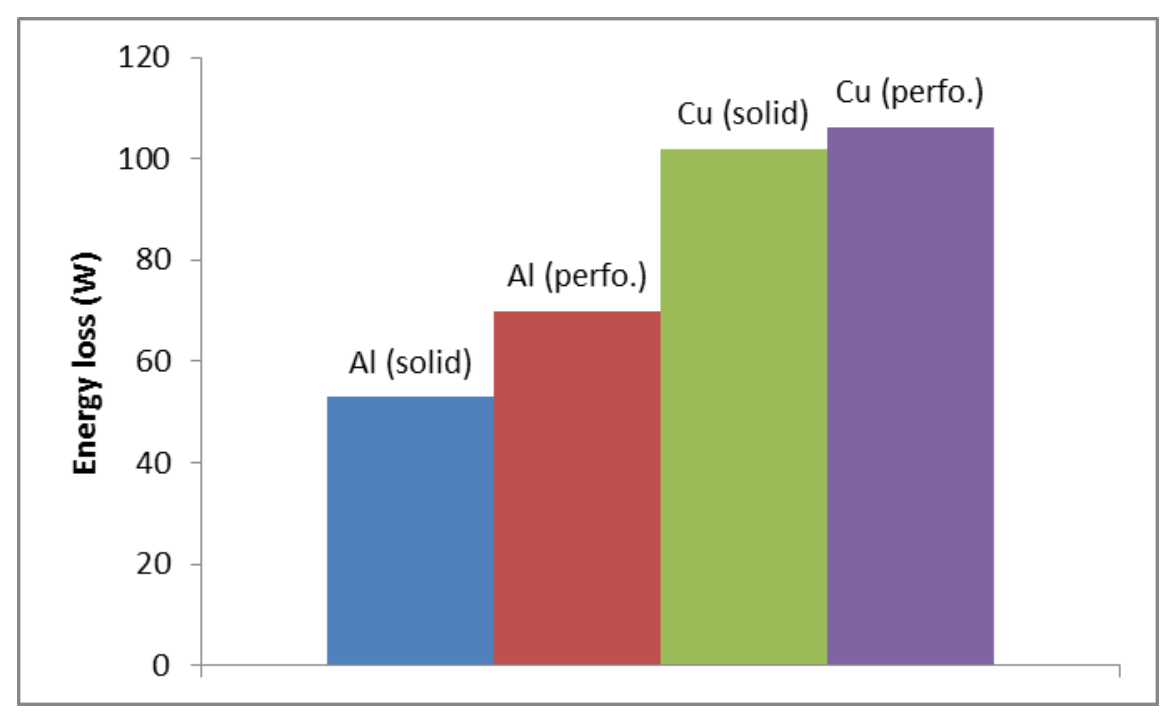

Fig.12. Comparison between heat loss for $\mathrm{Al}$ and $\mathrm{Cu}$ fins (solid and perforated)

\section{REFERANCES}

AlEssa A. H.., (2012), Augmentation of Fin Natural Convection Heat Dissipation by Square Perforations, Journal of Mechanical Engineering and Automation, vol. 2, 1-5.

Bahadure S. D., Gosavi G. D., (2014), Enhancement of Natural Convection Heat Transfer from Perforated Fin, International Journal of Engineering Research, Vol.3, No. 9, 531 -535..

Dewan A. , Patro P., Khan I., Mahanta P., (2009), The effect of fin spacing and material on the performance of a heat sink with circular pin fins, J. Power and Energy, Vol. 224, 35-46.

Holman J.P., (2010), Heat Transfer, $10^{\text {th }}$ edition, McGraw-Hill Book Company, New York. 
Jassem R. R., (2013), Effect the Form of Perforation on the Heat Transfer in the Perforated Fins, Journal of Natural and Applied Sciences, Vol. 4, No. 3, 198-207.

Kraus A.D., Abdul Aziz, Welty J., (2001) Extended surface heat transfer, $1^{\text {st }}$ edition, John Wiley and Sons, U.S.A .

Muthuraja C. S., kumar A., Hanoca P., (2015), Experimental Study of the Perforated Rectangular Fins by Natural Convection", International Journal of Advanced Technology in Engineering and Science, Vol. 3, Special No. 1, 303-307.

Prabisha M., Ramesh R., (2015), Thermal Performance Evaluation of Heat Sink for Various Fin Profiles, International Journal of Science, Technology \& Management, Vol. 4, No. 1, 462470.

Prasad L., Tewari S., Kumar A., (2016), An Experimental Study of Heat Transfer Enhancement in the Perforated Rectangular Fin, Journal of Integrated SCIENCE \& TECHNOLOGY, Vol. 4, No. 1, 5-9.

Ralph L. W, Kim N., (2005), Principles of Enhanced Heat Transfer, $2^{\text {nd }}$ edition, Taylor \& Francis group, New York.

Rohsenow W. M., Hartnett J. R., Cho Y. I., (1998), Handbook of Heat Transfer Applications, $3^{\text {rd }}$ Edition, McGraw-Hill Book Company, New York.

Shitole A.S., Arkirimath R. R., (2016), Experimental study and heat transfer analysis of effect of various perforations on vertical heated plates in natural convection, International Engineering Research Journal, Special No., 45-50.

Sonawane T., Patil P., Chavhan A., Prof. Dusane B.M., (2016), A Review on heat transfer enhancement by passive methodes, International Research Journal of Engineering and Technology, Vol. 3, No. 9, 1567-1574.

Thamir K., Basrawi F., Mohammed M. N., Ibrahim H., (2016), Effect of Perforation Area on Temperature Distribution of the Rectangular Fins under Natural Convection, ARPN Journal of Engineering and Applied Sciences, VOL. 11, NO. 10, 6371-6375.

Xuan, Y. M, Zhang, H. L, Ding, R., (2001), Heat transfer enhancement and flow visualization of wavy perforated plate and fin surface, in proc. Third International Conference on Compact Heat Exchanger and Enhancement Technology for the Process Industries. 